\title{
Cataract and Retinal Detachment Following Electric Shock Injury in a 28-year-old Nigerian Male: A case report
}

\author{
BJ Adekoya MBBS, FMCOphth, FWACS
}

Department of Ophthalmology, Lagos State University Teaching Hospital, Ikeja, Lagos, Nigeria

\section{SUMMARY}

Aim: To report a case of cataract and retinal detachment following an electrical injury in an adult Nigerian male.

Case report: A 28-year-old man presented with a history of progressive and painless loss of vision in the right eye, three years after an electric shock injury. There was no history of mechanical trauma. Examination and investigations revealed a mature cataract and retinal detachment in the right eye. He subsequently had an uneventful cataract surgery with expected poor prognosis, secondary to the retinal detachment.

Conclusion: This case highlights two ocular complications (one common and one uncommon) following an electrical injury. A high index of suspicion and awareness of the likelihood of these complications may increase diagnostic accuracy, especially in cases of presenile cataracts with no apparent cause.

Key words: electrical injury, presenile cataract, retinal detachment

\section{INTRODUCTION}

Systemic complications from electrical injury can be multisystemic, varied, debilitating, and are frequently fatal. ${ }^{1-3}$ Similarly, the ocular effects following electrical injury can be varied. ${ }^{4-13}$ Ophthalmic complications can be mild to severe in terms of visual morbidity, can occur acutely, early or late in terms of onset, and can be unilateral or bilateral. Changes have also been seen in the anterior as well as posterior segments of the eye, in addition to effects on ocular adnexia.

Local data relating to the prevalence and pattern of electrical injuries, both systemic and ocular manifestations, are scarce. In the United States, electrical burns account for $4 \%$ to $6.5 \%$ of all admissions to burn units and for approximately 1000 fatalities per year. ${ }^{14}$ However, complications from electrical injuries may be more common in our environment than we think. This may be related to the widespread handling of electricity, by professionals and non-professionals alike. There are high tension cables visibly surrounding most homes, and the electrical design of majority of old buildings and even some new ones is such that electric wires are run on the surface of the walls, where people can easily come into contact with them. In addition, the continued dependence on electrical generators has further increased people's contact with electricity. The impact of electrical trauma generally is, therefore, likely to become more important.

This is a case report of a unilateral cataract and retinal detachment secondary to electric shock in a 28 -year-old Nigerian male. It particularly highlights the need for a high index of suspicion in cases of presenile cataract, without a history of mechanical trauma.

\section{CASE REPORT}

$\mathrm{UZ}$ is a 28-year-old businessman who presented at the eye clinic of the Lagos State University Teaching Hospital, Ikeja, Lagos, Nigeria, with a 3-year history of gradual, painless, and progressive loss of vision in the right eye. There was no history of ocular trauma, redness, or photophobia. There was, however, a history of electrical injury about 3 years prior to the onset of the symptom. He accidentally touched an iron tank that was in contact with a live wire. There was associated loss of consciousness. He also sustained burns on the hands and legs, which were treated at a private hospital. He was not a known hypertensive (blood pressure $=120 / 80 \mathrm{mmHg}$ ) or diabetic, neither was he on chronic use of any systemic or topical ocular medications.

General examination revealed a healthy looking man with burn scars on the legs and hands (figure 1). Visual acuity was hand motion in the right eye and 6/9 in the left eye. There was exotropia RE of about $15^{\circ}$. The lids, conjunctiva, cornea, anterior chamber, iris, and pupils were normal in both eyes. There was dense white opacity of the lens in the right eye, which precluded a view of the fundus. Light projection and

${ }^{*}$ Correspondence: BJ Adekoya, Department of Ophthalmology, Lagos State University Teaching Hospital, Ikeja, Lagos, Nigeria.

E-mail: bjadekoya2007@yahoo.com 
colour discrimination were impaired. Slit lamp examination of the left eye revealed early lens opacity, and fundoscopy showed a normal posterior segment. Intraocular pressure was $14 \mathrm{mmHg}$ in both eyes. An assessment of bilateral cataract (right eye mature) secondary to electric shock was made based on the above history of severe electric shock in an otherwise healthy man.

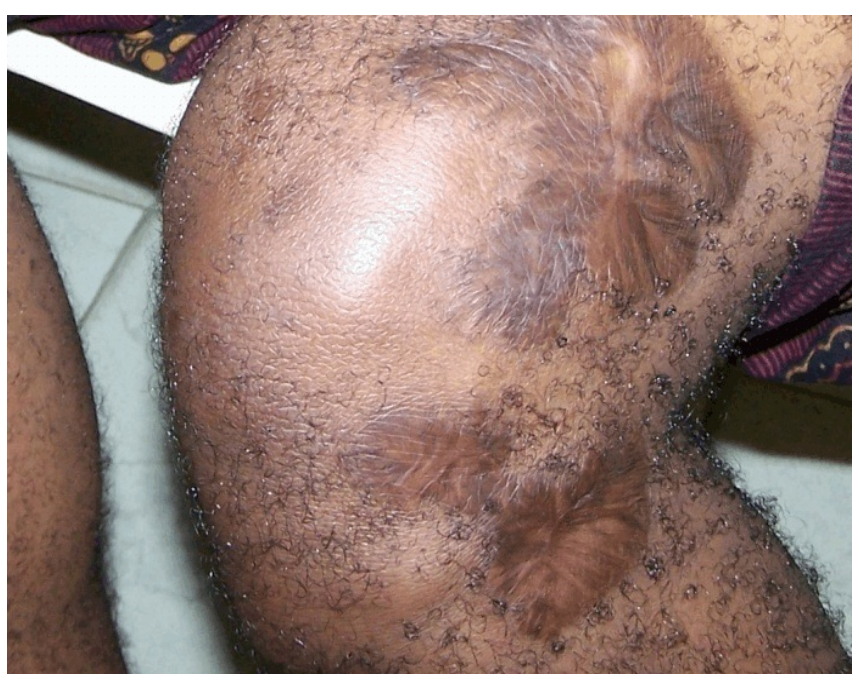

Figure 1. Burn scars on the leg of the patient.

He was investigated with the following results: full blood counts with differentials were essentially normal, genotype was AA, fasting blood sugar was $70 \mathrm{mg} / \mathrm{dl}$, VDRL negative, and intraocular lens power after biometry was +18.00D with a refraction of -0.06 . Ocular B-scan however revealed a right eye retinal detachment (figure 2).

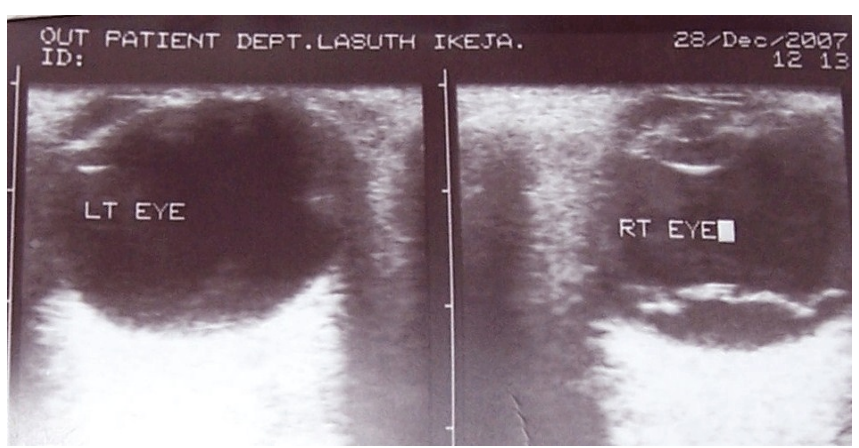

Figure 2. Ocular B-scan showing a right eye retinal detachment.

The patient was counselled on the poor visual prognosis and subsequently prepared for an extracapsular cataract extraction with insertion of posterior chamber intraocular lens. Fundal reflex was greyish intra operatively, but surgery was otherwise uneventful.
Visual acuity remained hand motion post operatively with a mild conjunctiva injection, clear cornea, round pupil and in-situ posterior chamber intraocular lens. He was commenced on routine post-operative drugs; topical antibiotic (neomycin), mydriatic (tropicamide), and steroids (bethamethasone). Post-operative fundoscopy confirmed a long-standing retinal detachment.

\section{DISCUSSION}

According to statistical data, $0.8 \%$ to $1 \%$ of all accidental deaths are caused by an electrical injury. ${ }^{2}$ Exact pathophysiology of electrical injury is not well understood, but is believed to be due to coagulative necrosis of tissue secondary to the thermal effects during passage of the electric current. ${ }^{14,15}$ Besides thermal burns, permeabilization of cell membranes and direct electroconformational denaturation of macromolecules such as proteins have also been identified as tissue-damage mechanisms. ${ }^{15}$ Factors determining the severity of electrical injury include; type of circuit (alternating vs. direct), duration of exposure, resistance of tissues, ${ }^{14}$ voltage, amperage, and pathway of the current. Electrical injuries have also been divided into low $(<1000 \mathrm{~V})$, and high $(>1000 \mathrm{~V})$ voltage injuries. Generally, the higher the voltage, the greater the resultant morbidity and mortality. Exposure to alternating current is more dangerous than direct current of the same voltage because of muscle tetany and the prolonged contact that occurs. ${ }^{14}$

In high-voltage injuries, patients may lose consciousness - as documented in the history of this particular patient - but this is usually temporary unless there is associated head injury. ${ }^{16}$ This case also highlights the entrance and exit wounds typical of electrical injury. Skin burn is a very important complication of electrical injury, and usually occurs and is most severe at the contact and exit points.

Ocular changes following electrical injury have been described in the literature. These changes include; burns of eyelids, cornea ulcer and opacity, anterior uveitis, ${ }^{4,9}$ anisocoria, ${ }^{9}$ cataract$^{4-13}$ macular cysts, ${ }^{9,}{ }^{11}$ macular holes, ${ }^{4}$ retinal detachment, ${ }^{5}$ central retinal vein occlusion, ${ }^{4}$ optic neuropathy, ${ }^{10}$ and so on. Although a number of these ocular changes occur immediately after injury, ${ }^{12}$ many develop days and even years after. ${ }^{5,8}$ The exact pathophysiology of these changes are not well understood.

The effect of electric current on the eyes of experimental animals has also been studied, ${ }^{13}$ though no histological or ophthalmological alterations in the retina, optic nerve or vasculature were observed using conventional techniques, limited by the survival potential of the exposed animals.

A well-known and frequently reported ocular complication following electrical injury is cataract, ${ }^{4-13}$ as presented in this case. Saffle et al. reported an incidence of $6.2 \%$ in patients that sustained major electrical injuries, 
especially when electrical injury occurs in the head area. ${ }^{5} \mathrm{~A}$ wide range of voltage - from 220 to 50,000 - has been reported to result in cataract., ${ }^{5}$ The exact pathogenesis of these cataracts is unknown, but direct coagulation of proteins and osmotic changes following damage to the subcapsular epithelium are thought to be responsible., ${ }^{47}$ This cataract is typically anterior and posterior subcapsular and has a coarse, fern-like appearance. It is usually bilateral, ${ }^{4,7,9,10,12}$ but can also occur unilaterally. ${ }^{12}$ However, closer examination even in unilateral cases may reveal early changes in the apparently uninvolved eye. ${ }^{8}$ The side closer to the contact wound usually presents earlier. A long latency period before development of cataract, as seen in this patient, is not unusual. ${ }^{5,8}$

These cataracts often need surgery, and surgical removal in these patients usually gives good results in the absence of other ocular complications. ${ }^{5,7,8,10,12}$ A return of excellent vision was not achieved in this patient because of associated retinal detachment. The mechanism of development of RD in electric injury may be the result of a macular hole sequel to persistent macular cysts. ${ }^{9,11}$

\section{CONCLUSION}

This case highlights one common and one uncommon ocular complication from electrical injury. A high index of suspicion in cases of presenile cataract with no apparent cause should suggest other predisposing factors - the possibility of an electrical injury should be considered in these cases.

\section{REFERENCES}

1. Demling RH. Electrical trauma: pathophysiology and clinical management. In: Lee RC, Cravalho EG, Burke JF, eds. Electrical Trauma: The pathophysiology, manifestations and clinical management. Cambridge: Cambridge University Press, 1992: 122-132.

2. Bailey B, Forget S, Gaudreault P. Prevalence of potential risk factors in victims of electrocution. Forensic Sci Int 2001; 123:5862.
3. Jensen PJ, Thomsen PEB, Bagger HP, et al. Electrical injury causing ventricular arrhythmias. Br Heart J 1987; 57: 279-83.

4. Boozalis GT, Purdue GF, Hunt JL, McCulley JP. Ocular changes from electrical burn injuries. A literature review and report of cases. J Burn Care Rehabil 1991; 12: 458-62.

5. Saffle JR, Crandall A, Warden GD. Cataracts: a long-term complication of electrical injury. J Trauma 1985; 25: 17-21.

6. Lock JAN. Electric cataract produced by a $240 \mathrm{~V}$ current. $\mathrm{Br} \mathrm{J}$ Ophthalmol 1957; 41: 500-501.

7. Chaudhuri Z, Pandey PK, Bhatia A. Electrical cataract; a case study. Ophthalmic Surg Lasers 2002; 33: 166-168.

8. Grewal DS, Jain R, Brar GS, Grewal SP. Unilateral electric cataract: Scheimpflug imaging and review of the literature. $J$ Cataract Refract Surg 2007; 33: 1116-1119.

9. Miller BK, Goldstein MH, Monshizadeh R, Tabandeh H, Bhatti MT. Ocular manifestations of electrical injury: a case report and review of the literature. CLAO J 2002; 28: 224-227.

10. Biro Z, Pamer Z. Electrical cataract and optic neuropathy. Int Ophthalmol 1994; 18: 43-47.

11. Manrique-Cerrillo M, Murillo-López S, Leizaola-Fernández C, et al. Bilateral macular cysts secondary to electric current strike. A case report. Arch Soc Esp Oftalmol 2004; 79: 37-39.

12. Mutlu FM, Duman H, Cil Y. Early-onset unilateral electric cataract: a rare clinical entity. J Burn Care Rehabil 2004; 25: 363365.

13. Herbert W. Electrical injuries to the eye. Graefe's Archive for Clinical and Experimental Ophthalmology. 1975; 193: 67-79.

14. Lee RC. Injury by electrical forces: pathophysiology, manifestations, and management. Curr Prob Surg 1997; 34: 677764

15. Lee RC, Zhang D, Hannig J. Biophysical injury mechanisms in electrical shock trauma. Annu Rev Biomed Eng 2000; 2: 477-509.

16. Kelley KM, Pliskin N, Meyer G, Lee RC. Neuropsychiatric aspects of electrical injury: the nature of psychiatric disturbance. Ann N Y Acad Sci 1994; 720: 213-218.

17. Bellows JG, Chinn H. Biochemistry of the lens. XIV. Pathogenesis of electric cataract. Arch Ophthalmol 1941; 26: 606612. 